\title{
Habitat Concepts for Deep Space Exploration
}

\author{
David Smitherman $^{*}$ \\ NASA Marshall Space Flight Center, Huntsville, Alabama, 35812 \\ and \\ Brand N. Griffin ${ }^{\dagger}$ \\ Gray Research, Huntsville, Alabama, 35806
}

\begin{abstract}
Future missions under consideration requiring human habitation beyond the International Space Station (ISS) include deep s pace habitats in the lunar vicinity to support asteroid retrieval missions, human and robotic lunar missions, satellite servicing, and Mars vehicle servicing missions. Habitat designs are also under consideration for missions beyond the Earth-Moon system, including transfers to near-Earth asteroids and Mars orbital destinations. A variety of habitat layouts have been considered, including those derived from the existing ISS designs and those that could be fabricated from the Space Launch System (SLS) propellant tanks. This paper presents a comparison showing several options for asteroid, lunar, and Mars mission habitats using ISS derived and SLS derived modules and identifies some of the advantages and disadvantages inherent in each. Key findings indicate that the larger SLS diameter modules offer built-in compatibility with the launch vehicle, single launch capability without on-orbit assembly, improved radiation protection, lighter structures per unit volume, and sufficient volume to accommodate consumables for long duration missions without resupply. The information provided with the findings includes mass and volume comparison data that should be helpful to future exploration mission planning efforts.
\end{abstract}

\section{Nomenclature}

\begin{tabular}{|c|c|c|c|}
\hline AES & $=$ Advanced Exploration Systems & $L A B$ & $\begin{aligned}= & \text { Lab size module such as the Destiny } \\
& \text { laboratory on the ISS }\end{aligned}$ \\
\hline CSA & $=$ Canadian Space Agency & $L E O$ & $=$ low-Earth-orbit \\
\hline$D R O$ & $=$ distant retrograde orbit & $m$ & $=$ meter \\
\hline ECLSS & $=$ Environmental Control and Life & $m^{3}$ & $=$ cubic meters \\
\hline & Support System & $m t$ & $=$ metric ton \\
\hline$E L V$ & $=$ expendable launch vehicle & MOI & $=$ Mars Orbit Insertion \\
\hline EML1 & $=$ Earth-Moon Lagrangian point 1 & $M P C V$ & $=$ multi-purpose crew vehicle (Orion) \\
\hline EML2 & $=$ Earth-Moon Lagrangian point 2 & MPLM & $=$ multi-purpose logistics module \\
\hline$E S A$ & $=$ European Space Agency & $N A S A$ & $=$ National Aeronautics and Space \\
\hline EUS & $=$ Exploration Upper Stage & & Adminis tration \\
\hline EVA & $=$ extra-vehicular activity & NEA & $=$ near-Earth asteroid \\
\hline$H A B$ & $=$ Habitat module & $O R U$ & $=$ orbital replacement unit \\
\hline ISECG & $=$ International Space Exploration & SLS & $\begin{array}{l}=\text { Space Launch System } \\
=\text { Trans-Earth Injection }\end{array}$ \\
\hline$I S R U$ & $=$ in-situ res ource utilization & $T M I$ & $=$ Trans-Mars Injection \\
\hline & $=$ International Space Station & $T R L$ & $=$ technology readiness level \\
\hline$k g$ & $=$ kilograms & USOS & $=$ United States Orbital Segment \\
\hline JAXA & $=$ Japan AerospaceExploration Agency & & \\
\hline
\end{tabular}

\footnotetext{
* Technical Management, Advanced Concepts Office, ED04, AIAA Senior Member.

${ }^{\dagger}$ Senior Engineer, Jacobs Engineering ESSSA Group Contract, 655 Discovery Drive, Suite 300, AIAA Senior Member.
} 


\section{Introduction}

$\mathrm{T}_{\mathrm{R}}^{\mathrm{H}}$ HE International Space Station(ISS) shown in Fig. 1 is composed of a Russian Orbital Segment developed by Russia Federal Space Agency, and a United States Orbital Segment (USOS) developed by the National Aeronautics and Space Adminis tration(NASA), European Space Agency (ESA), Canadian Space Agency (CSA), and Japan Aerospace Exploration Agency (JAXA). The USOS consists of pressurized habitable modules that are approximately $4.5 \mathrm{~m}$ in diameter with varying lengths between 5 and 11 meters. The sizes of these modules were dictated by the cargo bay size and lift capability of the Space Shuttle. There are several modules remaining in the ISS Program that have been considered for outfitting and utilization on orbit and were described in previous papers for ISS derived Deep Space Habitats. The modules considered included the habitat module (HAB), which was the structural test article for the Destiny module (LAB), the structural test article for the Unity module (Node 1), and two Multi-Purpose Logistics Modules (MPLM), Raffaello and Donatello. Although the Space Shuttle is no longer available to launch these modules, they could be us ed in future mis sions to deep space because they do fit within the payload capability of current expendable launch vehicles (ELV). Modifications to the structural load path of the ISS modules or remanufacturing might be required, but the basic size is right for ELV delivery to orbit.

Larger modules have also been considered based on the propellant tank diameter available from the new SLS vehicle manufacturing process. This concept was first introduced as Skylab $\mathrm{II}^{2}$ because of the similar approach taken to derive our first space station, Skylab (Fig. 2), from the third stage of the Saturn V rocket. Progress on that design concept includes the use of a standard length barrel section and two end domes from the SLS hydrogen tank manufacturing line to formone large pressure vessel at approximately $8.4 \mathrm{~m}$ in diameter with overall lengths of 11 and 14 meters. The diameter is ideal for integration onto the SLS vehicle, and the mass fits within the planned lift capabilities of the SLS with the large diameter Exploration Upper Stage (EUS) for $105 \mathrm{mt}$ and $130 \mathrm{mt}$ payload delivery to low-Earth-orbit (LEO). The following sections summarize the missions under consideration and the habitat designs developed to investigate and compare the advantages and dis advantages of the ISS and SLS derived modules.

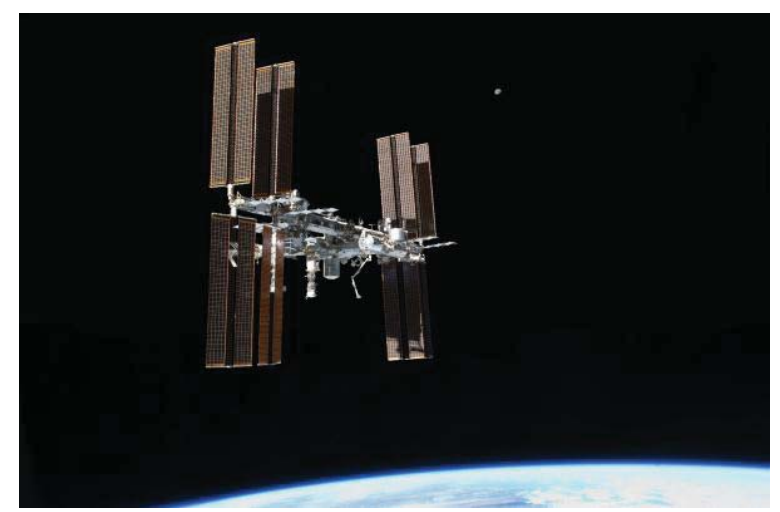

Figure 1. International Space Station. The ISS as seen in orbit from the last Space Shuttle mission, STS135, July 21, 2011.

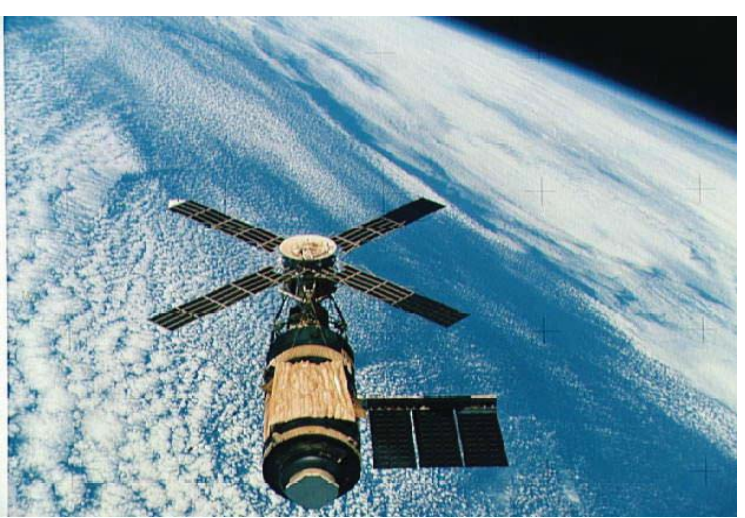

Figure 2. Skylab. The first US space station as seen in orbit from the Apollo Command Module on the last Skylab mission, SL-4, February 8, 1974.

\section{Mission Scenarios}

With the assembly of the ISS complete and the retirement of the Space Shuttle, new focus has been placed on developing a capability to extend human mis sions beyond low-Earth-orbit (LEO) and into deep space, including the Moon, as teroids, and Mars. Habitats under consideration to support these missions include those that would be human-tended and can be serviced in the lunar vicinity, and those capable of a long duration deep space transit beyond the Earth-Moon system to a near-Earth asteroid and Mars orbital destinations.

\section{A. Lunar Vicinity Missions}

Destinations in the vicinity of the Moon that are under consideration include the lunar surface, Earth-Moon Lagrangian points 1 and 2(EML1 and EML2 respectively), and several lunar orbits, including a distant retrograde orbit (DRO) that passes through EML1 and EML2 (Fig. 3). 


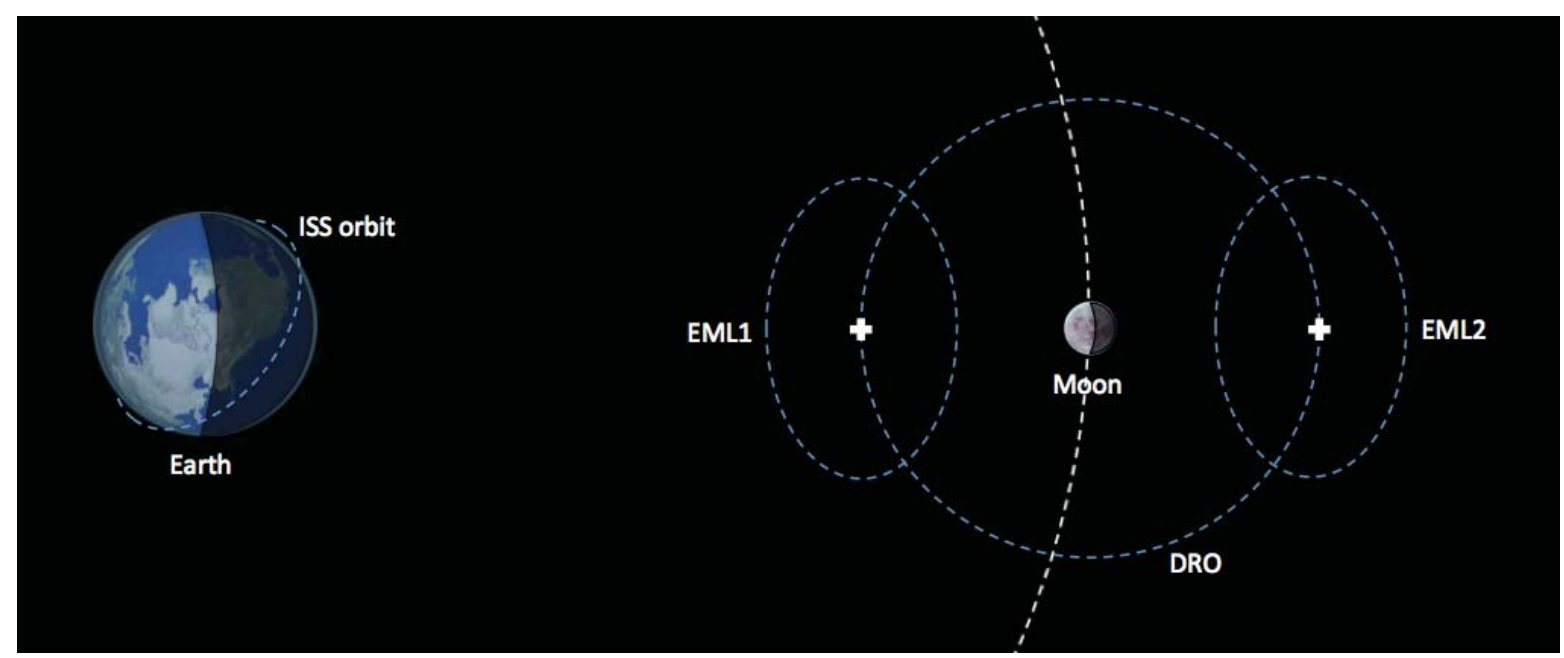

Figure 3. Deep Space Habitat Lunar Orbits. The orbits shown in this diagram are not to scale, but are representative of the lunar DRO, EML1, and EML2 orbital locations for the deep space habitats under consideration in recent years.

1) Asteroid Retrieval Missions: Recent studies have focused on a variety of approaches for supporting an asteroid retrievalmission. ${ }^{3}$ The basic concept is that a long duration habitat would be useful to support ongoing activities at an as teroid that has been moved into a lunar DRO. The DRO is a preferred location because it is a stable orbit requiring little or no station keeping propellants for orbital maintenance. Initial missions might include only an Orion multi-purpose crew vehicle (MPCV) with two crewmembers and extra-vehicular activity (EVA) support equipment. Long-term exploration could use a habitat to supplement the MPCV and enable longer missions with larger crews. Activities the habitat could support at the as teroid include life support for 4-crew up to 180 days, logistics resupply for ongoing human-tended operations, EVA and robotics support for sample collection, and setup of in-situ resource utilization (ISRU) experiments on the asteroid. An onboard laboratory could be provided to support initial sample examination and the selection of materials to return to Earth. Also, the laboratory can be used for the testing and repairing of ISRU systems, and for quarantine in the event microorganisms are discovered.

2) Lunar Missions: Habitats to support lunar missions were considered for locations in the lunar DRO, EML1, and EML2 orbits. The missions of interest included more direct control of lunar surface robotic systems, service for reusable robotic and human lander systems, initial analysis and curation of lunar sample materials collected from the surface of the moon, and assistance with setting up and serving of ISRU systems on themoon and in a laboratory inside the habitat using lunar materials. Although initial missions might use an MPCV and an expendable lander in a low lunar orbit, as done in the Apollo Program, a habitat at the higher orbits could support human-tended missions for 4-crew up to 180 days, provide global access to the lunar surface, and support lander reusability with the required servicing functions. It was found that these systems could be developed as an expansion of the capabilities described for the previous asteroid retrieval missions.

3) Mars Vehicle Servicing: Some Mars mission studies considered assembly of the Mars cargo and human transfer vehicles in a high-Earth orbit like the lunar DRO, EML1, and EML2 orbits described above because they reduce the change in velocity requirements for the transfer, thereby reducing the size and number of stages that have to be as sembled in orbit. With appropriate docking and robotics capabilities added to the deep space habitat, the servicing capabilities described for the asteroid retrieval and lunar mis sions can support a Mars vehicle assembly and servicing platform. This function would enable designed mis sions to reuse the Mars transfer habitat and other critical systems for ongoing Mars mission operations by returning these systems back to the deep space habitat prior to transferring the crew back to Earth. This concept will make many systems reusable and provide an additional level of planetary protection between Mars and Earth, if deemed necessary.

4) Deep Space Operations: Mission operations beyond LEO have significant differences for deep space habitats from the well-established procedures at the ISS. The radiation environment outside of the 
electromagnetic field that the ISS flies within is not fully understood. Although longer duration missions on board the ISS are planned for the near future and will be helpful to understand the effects of microgravity, they will not be able to address the additional radiation concerns that will be experienced in deep space. As a result, initial mission durations have been limited to 180 days until the impact of radiation in deep space on human health is better understood. Distance is another significant factor that will impact communication time and logistics. The deep space environment will force systems to become more autonomous and crews to become less dependent on ground support for mission plans, maintenance, and resupply. System autonomy, and vehicle maintenance and repair capabilities on board are important features for all deep space habitat systems.

5) International Participation: International organizations have shown an interest in deep space habitats as a natural expansion beyond the ISS. A recent publication from the International Space Exploration Coordination Group ${ }^{4}$ (ISECG) indicates a need for deep space habitats as a step on the path to the Moon and Mars. In addition, contributions in an international effort could take on any number of options, as demons trated in the ISS Program, and the Orion MPCV and SLS developments. An international initiative for es tablis hing a deep space habitat capable of supporting the multiple missions described above would seem like a logical step forward.

6) Commercial Crew and Cargo: Commercial participation will be critical too. Maintaining a deep space habitat in the lunar vicinity will eventually need resupply. Expanding the existing commercial cargo systems to deep space should be a natural fit. Commercial crew capabilities using existing ELV capabilities should be possible too with the development of refueling capabilities at the ISS or in LEO for transfers out to a habitat in deep s pace. Such developments should enable new commercial business capabilities that are compatible with exploration mission objectives.

\section{B. Asteroid and Mars Transit Missions}

Asteroid mis sions under consideration have included 4-crew human mis sions on yearlong trips out and back to a passing near-Earth as teroid (NEA). Mars mis sions under consideration include fly-by and orbital mis sions —orbital missions to the two Martian moons, Phobos and Deimos, and excursions to the surface of Mars with round trip times between 500 and 1000 days. Habitats are needed to support humans on all these missions, and both ISS derived and SLS derived habitats have been considered. All of the autonomy described in the former lunar orbit, deep space habitat missions are important precursors to deep space missions beyond 180 days.

\section{ISS Derived Concepts}

Several ISS derived concepts have been studied to determine the feasibility of using existing ISS modules available on the ground or fabricating new modules of a similar size and design. Two basic concepts are presented here to illus trate the potential they have for deep space habitats. All are at a vey high technology readiness level(TRL) because they are highly reliant on exiting ISS technologies. It is likely that these designs could be implemented through the existing ISS International Partner agreements and produced through the existing ISS contracting mechanisms. In other words, these vehicles could become an extension of the existing ISS Program. Both ISS derived concepts were planned for launch on multiple ELV's to the ISS for final assembly and outfitting.

\section{A. Configuration A using an ISS Node and MPLM}

Configuration A is shown in Fig. 4 and Fig. 5 and is designed to support 4-crew for 500 days with a Node 1 element and two MPLMs. The second MPLM between the MPCV and Node is designed primarily for logistics storage and the additional systems needed for 500-day missions. If it were removed, the vehicle could still support 4-crew, but only for 60-day missions.

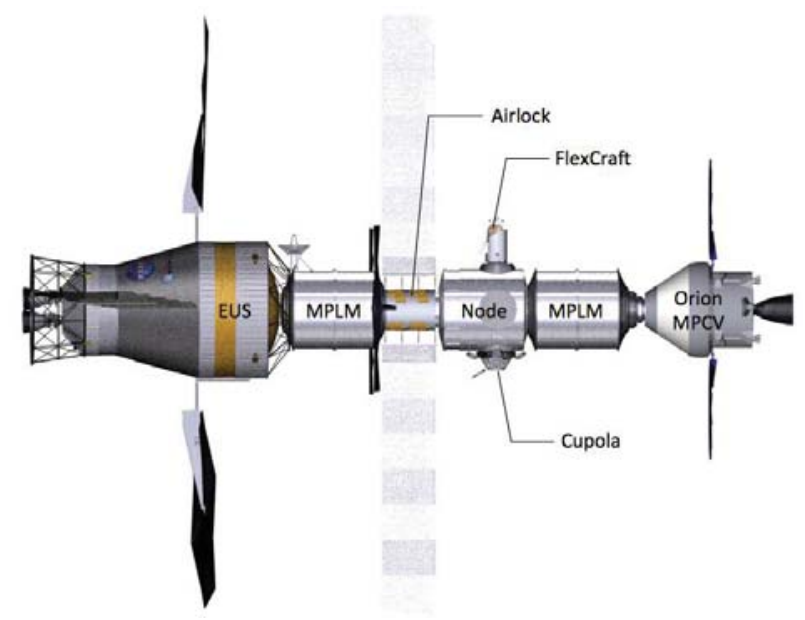

Figure 4. External View of Configuration A. This configuration supports 4-crew for 500 days with two MPLMs. The propulsion element is a notional EUS concept and was not sized for any particular mission. 


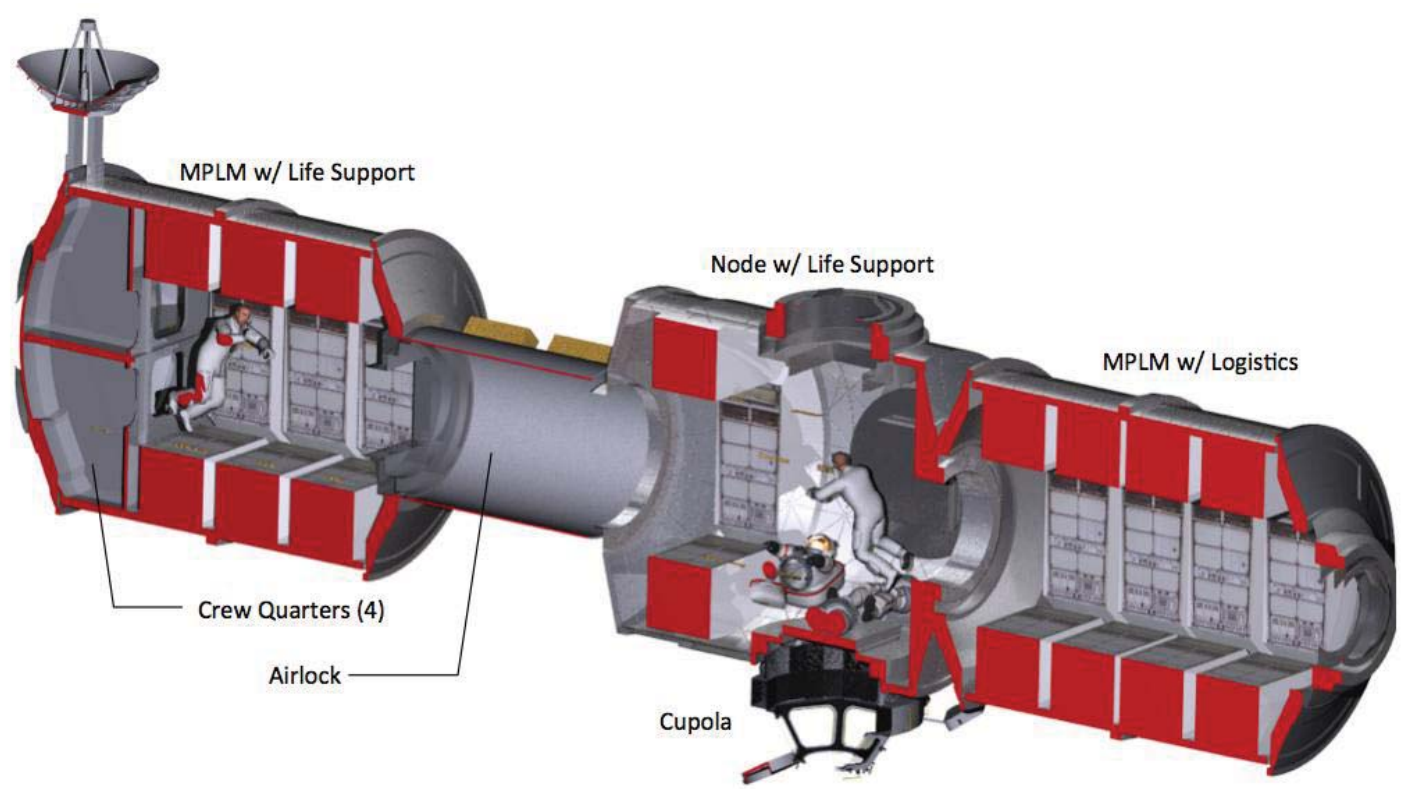

Figure 5. Internal Section View of Configuration A. The Node 1 module is in the center of this configuration with the primary MPLMand connecting tunnel/airlock on the left axialportand the logistics MPLM on the right axial port. The interior layout uses the standard ISS rack system except for the crew quarter built in to the end dome of the primary MPLM.

The Node 1 module has two axial and four radial ports. One axial port has the second logistics MPLM attached and the other has a tunnel structure designed for use as an airlock and strong back for externally mounted solar arrays, batteries, and radiators. The other end of the tunnel has the primary MPLM containing most of the crew support functions, and beyond the primary MPLM is a large chemical propulsion element. The propulsion element is a notional concept for the EUS and was not sized as a part of this study. The Node 1 radial ports contain a single person, free-flyer vehicle called FlexCraft ${ }^{5}$ on one side and an ISS derived cupola on the other-both specifically designed to support robotic and EVA assembly, and exploration operations. An ISS derived robotic arm is also envisioned to be a part of the robotic systems available on this habitat. The other two radial ports are open for a commercial logistics resupply module and an internationally developed reusable lunar lander.

The interior layout illus trated in Fig. 5 uses ISS systemracks for all equipment except the crew quarters that are built into the end dome of the primary MPLM element. Surrounding the crew quarters is a water wall for radiation protection, so the crew can retreat to their quarters during a solar particle event (SPE). Not all of the primary and secondary systems could fit in to the MPLM with this layout, so the racks in the Node are also used for life support functions. The total mass of the 500-day habitat is $49,578 \mathrm{~kg}$ with a pressurized volume of $281 \mathrm{~m}^{3}$ and a habitable volume of $108 \mathrm{~m}^{3}$. The 60 -day habitat removes the second MPLM yielding a habitat mass of 30,007 $\mathrm{kg}$ with a pressurized volume of $185 \mathrm{~m}^{3}$ and a habitable volume of $76 \mathrm{~m}^{3}$. For comparative purposes, the 60-day configuration is considered suitable for all lunar vicinity missions described in section II-A, and the 500-day configuration is considered suitable for the asteroid and Mars miss ions described in section II-B.

\section{B. Configuration B using HAB and MPLM}

Configuration B is shown in Fig. 6 and Fig. 7 and is designed to support 4-crew for 500 days with a HAB module element and one MPLM. The MPLM between the Orion MPCV and the HAB is designed primarily for logistics storage needed for 500-day missions. If it were removed, the vehicle could still support 4-crew, but only for 60-day missions.

The MPLM has two axial ports. One axial port has the MPCV attached and the other has a tunnel structure designed for use as an airlock and a strong back for externally mounted solar arrays, batteries, and radiators. The other end of the tunnel has the primary HAB attached, containing the crew life support functions. Beyond the HAB is a notional EUS. The tunnel/airlock can accommodate an EVA hatch and the FlexCraft ${ }^{5}$, as indicated in Configuration A, section III-A. An ISS derived robotic arm is also envisioned to be a part of the robotic systems available on this habitat. 
The interior layout is illus trated in Fig. 7 and does not use ISS system racks. All systems are built into orbital replacement units (ORU) for on-orbit servicing. The crew quarters are built into the end dome of the HAB module similar to configuration A. Surrounding the crew quarters is a water wall for radiation protection. Not all of the primary and secondary systems could fit in the MPLM used in Configuration A, but with this layout the larger HAB module accommodates all crew habitation systems, and the attached MPLM is required only for logistics sized for number of crew and mission duration. The totalmass of the 500 -day habitat is $45,573 \mathrm{~kg}$ with a pressurized volume of $193 \mathrm{~m}^{3}$ and a habitable volume of $90 \mathrm{~m}^{3}$. The 60 -day habitat removes the MPLM yielding a habitat mass of $28,750 \mathrm{~kg}$ with a pressurized volume of $117 \mathrm{~m}^{3}$ and a habitable volume of $65 \mathrm{~m}^{3}$. For comparative purposes, the 60 day configuration is considered suitable for all lunar vicinity missions described in section II-A, and the 500-day configuration is considered suitable for the asteroid and Mars missions described in section II-B.

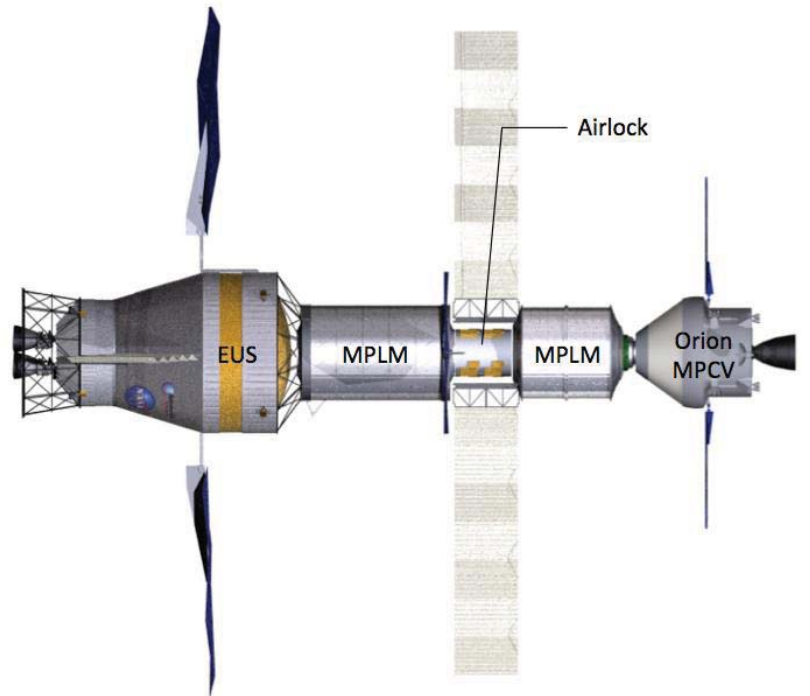

Figure 6. External View of Configuration B. $A$ $H A B / M P L M$ habitat is shown with a connecting tunnel/airlock, a propulsion element at one end and the MPCV at the other, for a 4-crew/500-day configuration.

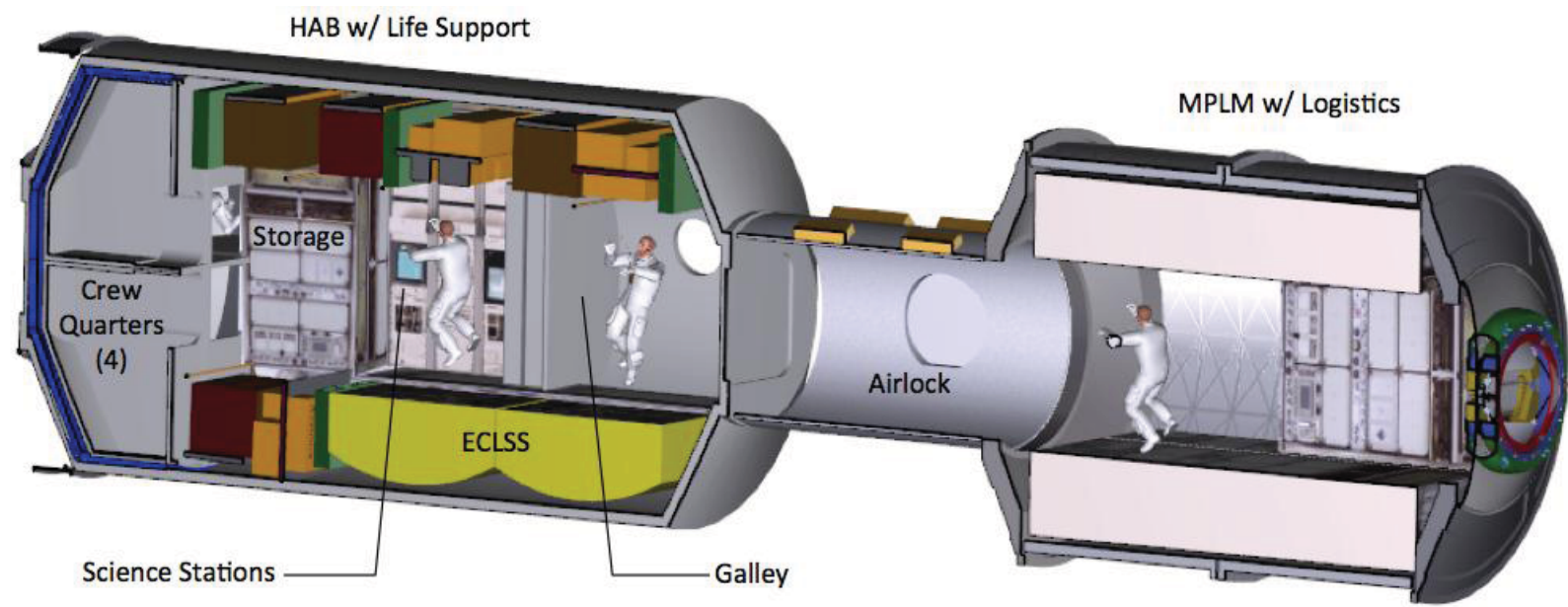

Figure 7. Internal Section View of Configuration B. The habitable elements include the HAB module with all crew life support systems, a connecting tunnel/airlock, and a MPLMfor logistics to support the mission crew size and duration. All internal equipment is built into the modulefor on orbit servicing and does not use the ISS rack system.

\section{SLS Derived Concepts}

This section presents three possible SLS derived concepts based on the $8.4 \mathrm{~m}$ diameter SLS core stage, which are similar to the concept known as Skylab II ${ }^{2}$ from previous publications. All three configurations match the SLS vehicle diameter, such that the cylindrical section aligns with the main structural loads path of the launch vehicle and requires only an aeroshell around the module to protect the multilayer insulation (MLI) and provide protection from micrometeoroid impacts. Minimum Capability and Full Capability configurations were designed for the lunar vicinity to explore the upper and lower bounds of possible configurations for mis sions described in section II-A, and the Mars Transit Habitat configuration was designed for deep space and is applicable to missions described in section II-B for asteroid and Mars destinations. 


\section{A. Configuration C-1 Minimum Capability}

Configuration C-1 is shown in Fig. 8 and is designed to support 4-crew for 180 days with a single large diameter module and an attached airlock. All logistics are stored within the module, primarily on the mid-deck level around the crew quarters to maximize radiation protection. Logistics storage is also available on the lower and upper decks for longer duration missions.
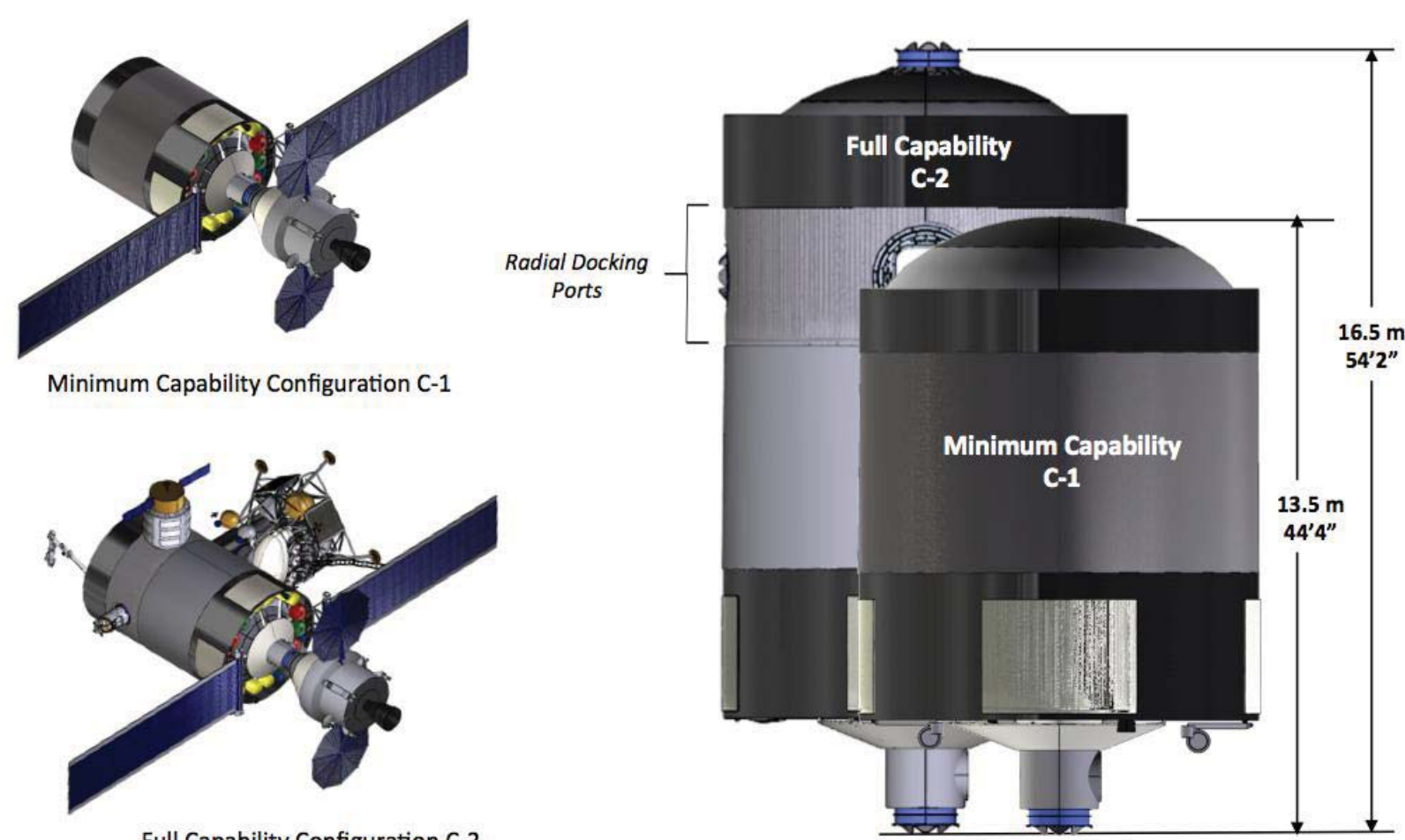

Full Capability Configuration C-2

Figure 8. External Views of Configurations C-1 \& C-2. The SLS derived habitats are the same diameter as the SLS core stage. The barrel sections utilize standardlengths from the hydrogentank plus an extended section for the radial ports in the $C-2$ Full Capability Configuration.

The SLS derived module in Configuration C-1 for Minimum Capability has one axial port on the airlock aft end for attachment of the Orion MPCV. The airlock is also equipped with a side EVA hatch for easy access to external utility systems. An additional port is possible at the dome opposite the airlock end or forward end. The aft end supports external propulsion systems to assist in maneuvers to the lunar DRO from a separate EUS, and is designed for refueling to accommodate transfers between the lunar DRO and the EML1 and EML2 orbits.

The interior layout is illus trated in Fig. 9 and uses a combination of equipment pallets, storage compartments, and acoustical panels to form the interior space on three levels. The crew quarters is located in the center of the mid deck for maximum radiation protection fromsurrounding systems; therefore, no additional mass is required from water walls or polyethylene panels, as provided in the previous ISS derived configurations or in use on the ISS. The lower deck provides a subsystems area for pallet mounted equipment and an exercise area; the mid-deck provides the crew quarters as mentioned, two crew workstations and a waste/hygiene management compartment; and the upper deck provides a galley/wardroomand two additional crew workstations. Vertical translation to each deck is provided through the two end domes.

The total mass of the C-1 Minimum Capability habitat is $21,788 \mathrm{~kg}$ with a pressurized volume of $496 \mathrm{~m}^{3}$ and a habitable volume of $353 \mathrm{~m}^{3}$. Unlike the ISS derived habitats, the 60-day and 180-day habitat configurations have the same mass and volume. The system is designed to launch all logistics required for three 60-day missions or any combination of mission durations up to 180 days for 4-crew prior to resupply.

\section{B. Configuration C-2 Full Capability}

Configuration C-2 is also shown in Fig. 8 for comparis on of the similarities between the Minimum and Full Capability configurations. It is designed to support 4-crew for 180 days using a single large diameter module with an 
additional ring section at the forward end to accommodate radial ports. All logistics are stored within the module, primarily on the mid-deck level around the crew quarters to maximize radiation protection.

The SLS derived module configuration C-2, Full Capability, has a total of six docking and berthing ports. There is a 30" docking port on the airlock aft end for attachment of the Orion MPCV as provided in the Minimum Capability configuration, a 30" docking port on the forward dome, two radial30" docking ports , and two radial 50" berthing ports. The lower left illus tration in Fig. 8 shows the MPCV attached to the aft axial docking port, a logis tics module berthed to a 50 " radial port via robotic arm, a lunar lander docked to a 30 " docking port, and a FlexCraft ${ }^{5}$ docked to a 30 " docking port-leaving a 50" radial berthing port and 30" axial docking port open for expansion.

The airlock at the aft end is equipped with a side EVA hatch for easy access to external systems. As included in the C-1 Minimum Capability configuration, the aft end also supports external propulsion systems to assist in maneuvers to the lunar DRO from a separate EUS, and is designed for refueling to accommodate transfers between the lunar DRO and the EML1 and EML2 orbits.

The interior uses the same layout as illustrated in Fig. 9 and as described in section IV-A for the C-1 Minimum Capability configuration. The only difference is that there is additional interior volume at the forward end to accommodate the extended barrel section for the radial ports. The total mass of the C-2 Full Capability habitat is $27,434 \mathrm{~kg}$ with a pressurized volume of $662 \mathrm{~m}^{3}$ and a habitable

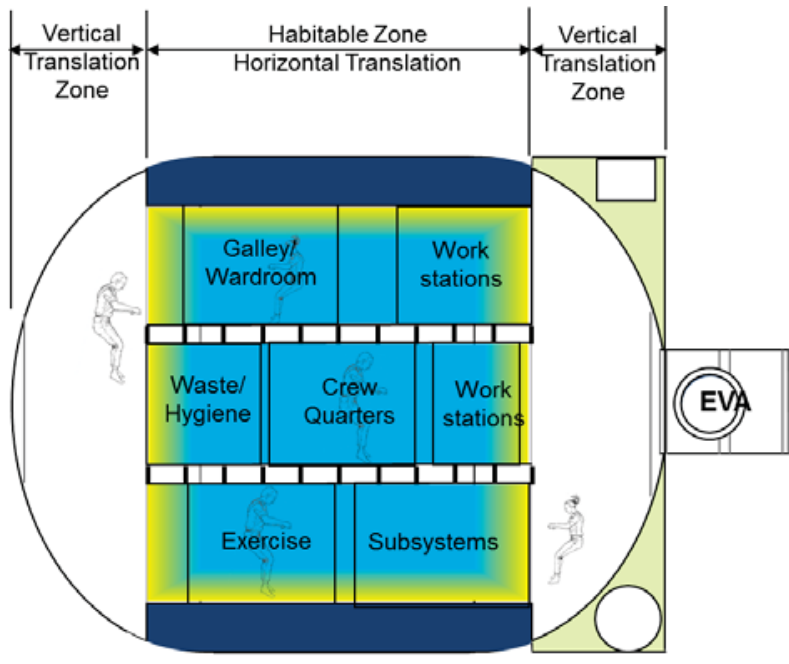

Figure 9. Internal Section View of Configuration C-1. The internal configuration for both $C-1$ and $C-2$ is similar with the crew quarters located in the center to maximize radiation protection. volume of $519 \mathrm{~m}^{3}$.

\section{Configuration C-3 Mars Transit Habitat}

Configuration C-3 for the Mars Transit Habitat is shown in Fig. 10. It is designed to support 6-crew for 1000 days using a single large diameter module with an additional ring section at the aft end to accommodate two radial ports, and an attached airlock at the forward end with a docking port for the Orion MPCV. The radial ports accommodate a FlexCraft vehicle and an open port for docking to a Mars lander that would be pre-deployed in Mars orbit. The overall mis sion concept is similar to current design reference mis sions ${ }^{6,7}$ except that it is aggregated and launched from the lunar DRO and uses higher TRL systems for propulsion and habitation. All logistics are stored within the module on all three decks, primarily along the outer walls to maximize radiation protection for the entire module. The airlock at the forward end is equipped with a side EVA hatch for access to external systems .

The interior of the C-3 Mars Transit Habitat uses a similar layout to the previous SLS derived habitats (Fig. 9). A floor plan is shown in Fig. 11, where the only difference is the accommodations for 6-crew and additional interior volume at the aft end for the two radial ports. The total mass of the C-3 Mars Transit Habitat is $41,369 \mathrm{~kg}$ with a pressurized volume of $662 \mathrm{~m}^{3}$ and a habitable volume of $440 \mathrm{~m}^{3}$.

The layouts shown for all three configurations are called longitudinal or horizontal layouts because they stretch horizontally along the length of the barrel section. Vertical or trans verse layouts were explored too, where the barrel section is turned up in a vertical orientation and the decks stack on top of each other in three or more levels. ${ }^{8}$ In general, it was found that the vertical layouts were slightly more massive due to the inefficiency of the layout on each floor-which had to accommodate the circular exterior wall in plan and pass-through at each floor to accommodate vertical circulation. It should be noted, however, that a vertically oriented layout might be appropriate for artificial gravity configurations where a vehicle, like the one shown in Fig. 10, could be rotated end-over-end during non-propulsive coast phases. 


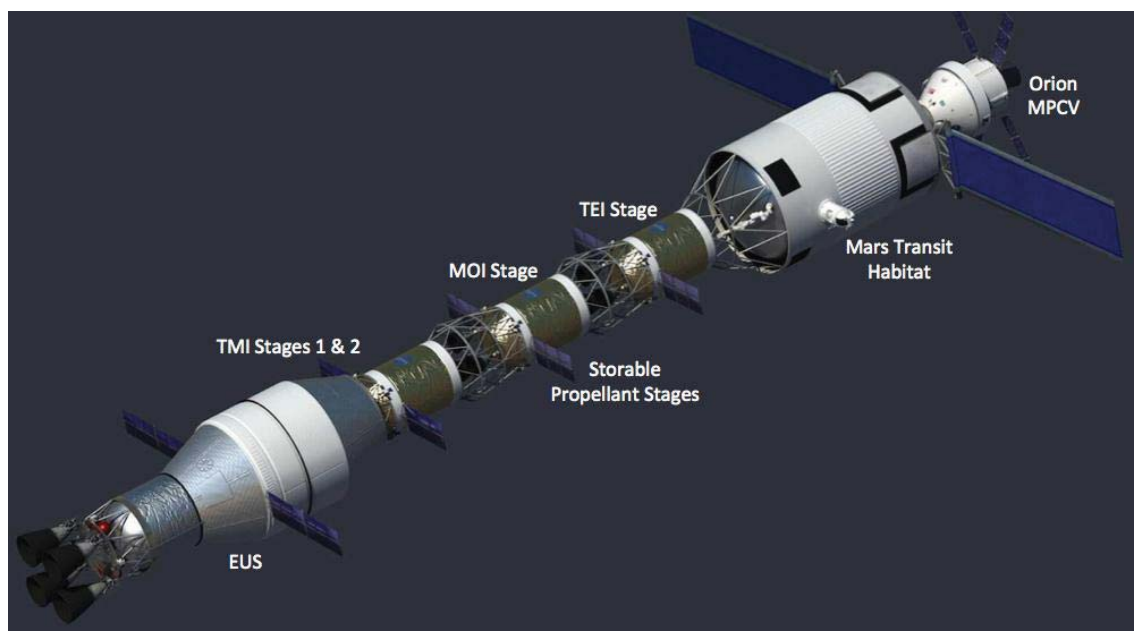

Figure 10. External Configuration C-3 for the Mars Transit Habitat. The configuration for Mars transfer is similar to the C-2 Full Capability. The transitvehicle includes one EUS and threestorable propellant stages for TMI, MOI, and TEI maneuvers. The Mars Transit Habitat and Orion MPCV are shown at the forwardendof the vehicle stack.

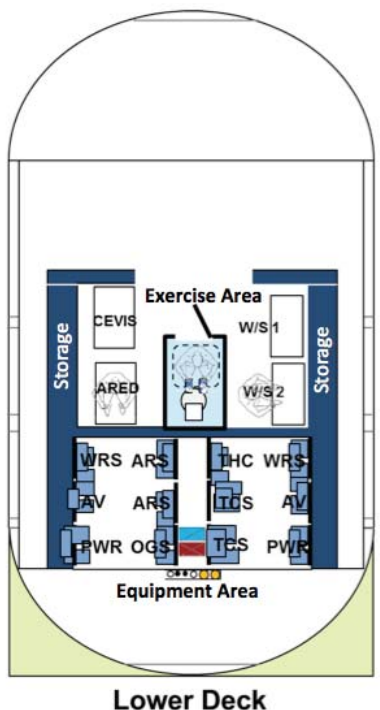

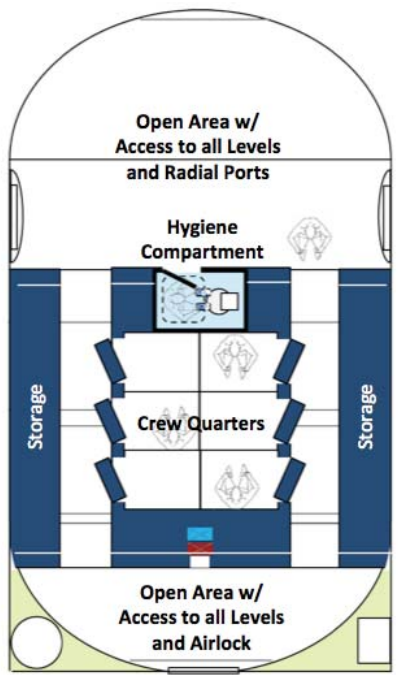

Main Deck

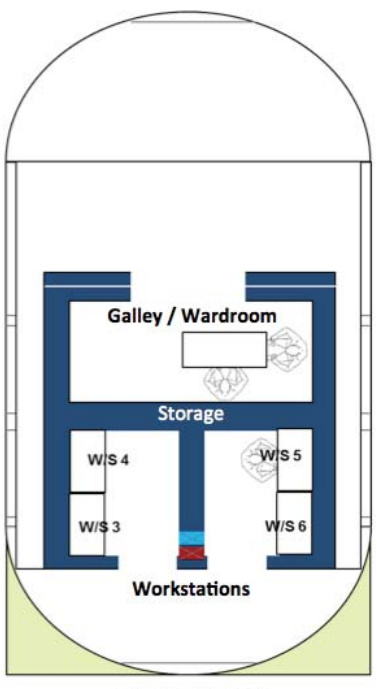

Upper Deck

Figure 11. Internal Plans for Configuration C-3. The internal layouts for all three configurations are similar. The C-3 Mars Transit Habitat accommodates 6-crew and is extended to accommodate two radial ports.

\section{Architectural Comparisons}

A comparis on of the two spacestations with the various habitat concepts discussed in this paper are shown in Fig. 12. The first two columns show the mass and volume for the Skylab and the ISS. Note that the mass of the ISS is an order of magnitude larger than the Skylab, but the volume is only about a third larger. This is due in part to the large number of experiment racks on the ISS, however, the primary difference is in the structures and systems required for each individual module. For example, the Skylab has one docking mechanism for the Apollo Command Module. The ISS has two to six docking or berthing mechanisms on each module, has over ten pressurized modules (each of which require duplicate support systems), and numerous docking and berthing adapters. Many of these duplicate structures and supporting systems can be eliminated when combined into one large volume module. 
Another factor to consider is cost, where time is money. It is significant to note that the Skylab was put in place with one launch of a Saturn V rocket in 1973 and was immediately usable for the next few years. Resupply could have enabled ongoing operations for many years had a reliable transportation system remained in place. The ISS took over 30 flights by the US Space Shuttle and the Russian Proton and Soyuz rockets to assemble from 1998 to 2010. The tremendous launch cost, development, and operations over this twelve-year assembly period was significant.

The mass and volume for the ISS derived and SLS derived configurations described in this paper are shown in the remaining columns (Fig. 12). It is significant to note that the mass for all the configurations are in the same range varying fromabout $22 \mathrm{mt}$ to $50 \mathrm{mt}$, but the volume available in the SLS derived configurations is two to six times larger than the ISS derived concepts with lower overall mass. In addition, it is significant to note that the SLS derived concepts were designed for delivery with one launch from the SLS, whereas the ISS concepts varied with three or more ELV launches with some on-orbit as sembly required.

The advantages the ISS derived habitats provide include the technologies, components, and integrated systems that are already in place and do nothave to be reinvented. Examples include the existing pressure ves sels that have not flown, docking and berthing systems, robotic arm and manipulator systems, life support systems, and all the utilities that provide power and thermal control. Many of these systems were designed for the ISS sized module and can be easily reproduced for future applications.

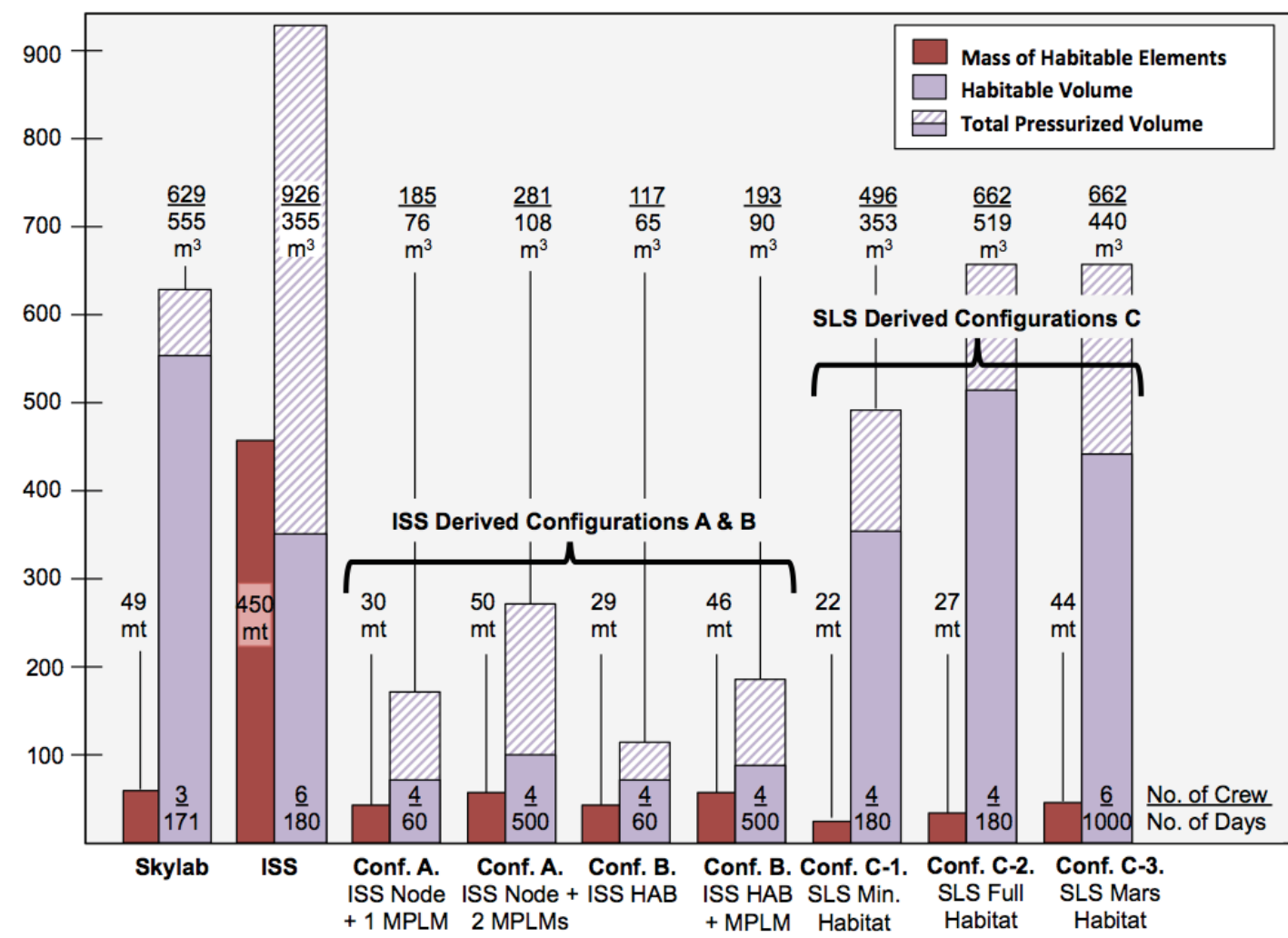

Figure 12. Mass and Volume Comparis on. The low mass and large volume of the Skylab and SLS derived concepts in comparison to the high mass and low volume of the ISS and ISS derived concepts.

\section{Conclusions}

Comparing the mass and volume of the various habitats described in this paper was similar to comparing apples and oranges because of the different requirements, crew sizes, and mission durations. However, there are some overall observations that are significant and should be considered in the design of future habitats. Fig. 12 provides one view for comparing overall mass with both habitable and pressurized volumes showing the significance of large diameter, large volume habitat modules. Large diameter SLS modules offer significant mass savings per unit volume, built-in compatibility with the launch vehicle, single launch capability without on-orbit as sembly, interior layouts with improved radiation protection, sufficient volume to accommodate consumables for long duration missions, and significant cost savings through the use of launch vehicle components and single launch capability. 
More information on themass and volume of the various concepts is provided in the Appendix. The ISS systems have advantages too, as demonstrated over the past two decades of as sembly and operations. Future developments should be a combination of both that brings forward the best of the ISS technologies into the next generation of SLS derived space station systems.

\section{Appendix}

Habitat Summaries: The following habitat summaries (Fig. 13 through Fig. 16) provide more detail for a comparis on of the various habitat configurations considered from 2011 to 2013. The average TRL is high due to reliance on existing ISS and Orion technologies to the greatest extent possible. The Mass Growth Allocation is based on AIAA estimating standards for the high utilization of TRL 9 systems. Science equipment, propulsion systems, and propellants were removed for comparative purposes since they can vary based on the mission and destination.

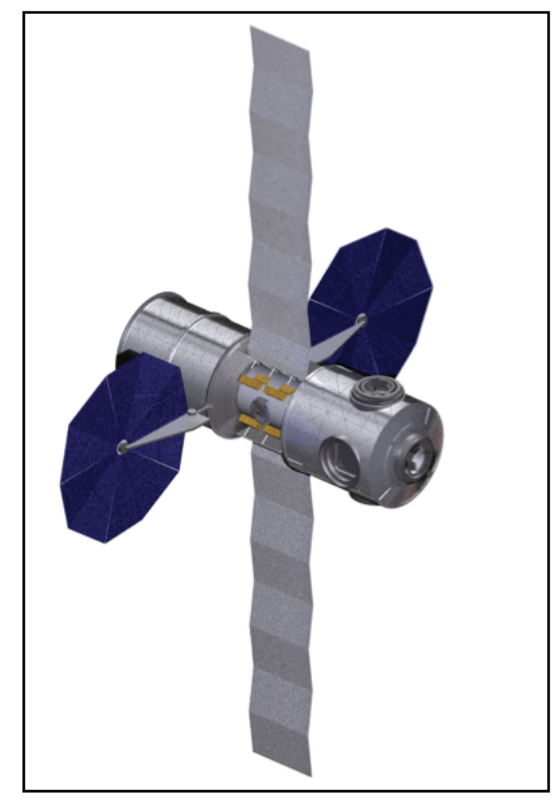

\begin{tabular}{|l|c|}
\hline $\begin{array}{l}\text { Design Constraints/Parameters } \\
\text { Pressurized Volume }\end{array}$ & $\sim 785 \mathrm{~m}^{3}$ \\
\hline Habitable Volume & $\sim 76.3 \mathrm{~m}^{3}$ \\
\hline Atmospheric Pressure (1 ATM) & $101.3 \mathrm{kPa}$ \\
\hline Crew Capacity & 4 \\
\hline Crewed Mission Duration (days) & $60 \mathrm{~d}$ \\
\hline EOL Solar power generation & $25.8 \mathrm{~kW}$ \\
\hline Power load during battery operation & $15.2 \mathrm{~kW}$ \\
\hline Average TRL & 8.1 \\
\hline TRL 9 / Heritage & $65 \%$ \\
\hline $\begin{array}{l}\text { ECLSS Closure - Water } \\
\text { ECLSS Closure - Air }\end{array}$ & Closed Loop \\
\hline Habitat Structure & Closed Loop \\
\hline Habitat Length & Rigid Cylinder \\
\hline Habitat Diameter & $13 \mathrm{~m}$ \\
\hline Mass Growth Allocation & $4.5 \mathrm{~m}$ \\
\hline Project Manager's Reserve & $7.64 \%$ \\
\hline
\end{tabular}

\begin{tabular}{|l|c|}
\hline Category & Mass $\mathbf{( k g})$ \\
\hline Structures & 11,756 \\
\hline Propulsion & 0 \\
\hline Power & 698 \\
\hline Avionics & 1,238 \\
\hline Thermal & 2,659 \\
\hline Environment Protection & 3,993 \\
\hline ECLSS & 3,379 \\
\hline Crew Systems & 775 \\
\hline EVA & 272 \\
\hline Science & 0 \\
\hline Dry Mass & $\mathbf{2 4 , 7 6 9}$ \\
\hline & \\
\hline Stowed Provisions & 1,305 \\
\hline Consumables & 976 \\
\hline Non-Propellant Fluids & 229 \\
\hline Inert Mass & $\mathbf{2 , 5 1 0}$ \\
\hline & \\
\hline Total Less Propellant & $\mathbf{2 7 , 2 7 9}$ \\
\hline Propellant & 0 \\
\hline Wet Mass & $\mathbf{2 7 , 2 7 9}$ \\
\hline & \\
\hline Project Mgrs Reserve (10\%) & 2,728 \\
\hline Total & $\mathbf{3 0 , 0 0 7}$ \\
\hline
\end{tabular}

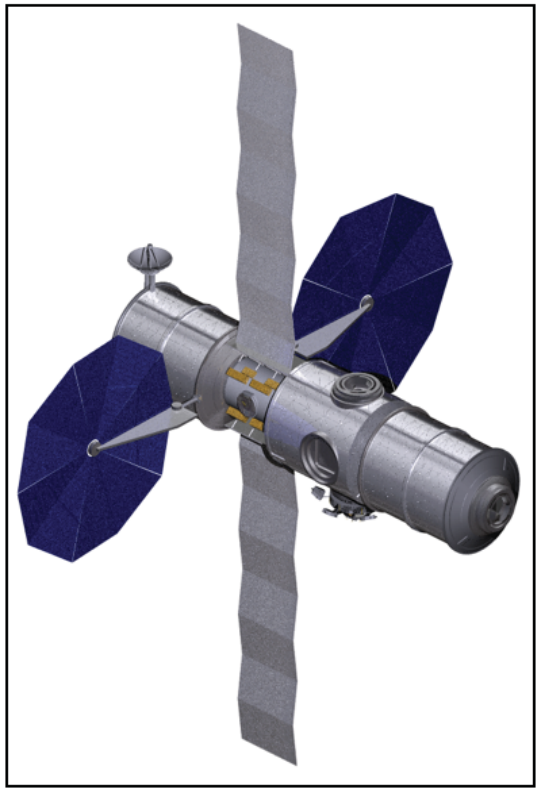

\begin{tabular}{|l|c|}
\hline $\begin{array}{l}\text { Design Constraints/Parameters } \\
\text { Pressurized Volume }\end{array}$ & $\sim 281 \mathrm{~m}^{3}$ \\
\hline Habitable Volume & $\sim 108.3 \mathrm{~m}^{3}$ \\
\hline Atmospheric Pressure & $101.3 \mathrm{kPa}$ \\
\hline Crew Capacity & 4 \\
\hline Crewed Mission Duration & $500 \mathrm{~d}$ \\
\hline EOL Solar power generation & $34 \mathrm{~kW}$ \\
\hline Power load during battery operation & $20 \mathrm{~kW}$ \\
\hline Average TRL & 8.1 \\
\hline TRL 9 / Heritage & $65 \%$ \\
\hline & \\
\hline ECLSS Closure - Water & Closed Loop \\
\hline ECLSS Closure - Air & Closed Loop \\
\hline Habitat Structure & Rigid Cylinder \\
\hline Habitat Length & $20 \mathrm{~m}$ \\
\hline Habitat Diameter & $4.5 \mathrm{~m}$ \\
\hline Mass Growth Allocation & $8.35 \%$ \\
\hline Project Manager's Reserve & $10 \%$ \\
\hline
\end{tabular}

\begin{tabular}{|l|c|}
\hline Category & Mass (kg) \\
\hline Structures & 19,955 \\
\hline Propulsion & 0 \\
\hline Power & 924 \\
\hline Avionics & 1,383 \\
\hline Thermal & 2,744 \\
\hline Environment Protection & 4,603 \\
\hline ECLSS & 4,607 \\
\hline Crew Systems & 964 \\
\hline EVA & 272 \\
\hline Science & 0 \\
\hline Dry Mass & $\mathbf{3 5 , 4 5 2}$ \\
\hline Stowed Provisions & \\
\hline Consumable Fluids & 3,416 \\
\hline Non-Propellant Fluids & $\mathbf{5 , 9 7 3}$ \\
\hline Inert Mass & $\mathbf{9 , 6 1 8}$ \\
\hline Total Less Propellants & 45,070 \\
\hline Propellant & 0 \\
\hline Wet Mass & $\mathbf{4 5 , 0 7 0}$ \\
\hline Project Mgrs Reserve (10\%) & 4,507 \\
\hline Total & $\mathbf{4 9 , 5 7 8}$ \\
\hline
\end{tabular}

Figure 13. Configuration A for the ISS Derived Node + Airlock + 1 \& 2 MPLMs. The two habitats shown provide habitation for 4-crew on 60-day missions, or 500-daymissions with the addition of a second MPLM. The habitat has six docking or berthing ports to accommodate the Orion MPCV, FlexCraft, cupola, and a EUS 
propulsion element. The two open ports could accommodate a lander and logistics module. The connecting tunnel is an airlock andincludes an EVA hatch with access to external utilities, including power and thermal systems. The habitat is designed to accommodate all life support systems in the Node and one MPLM. The second MPLM can be sized to provide consumables for mission durations beyond 60 days.

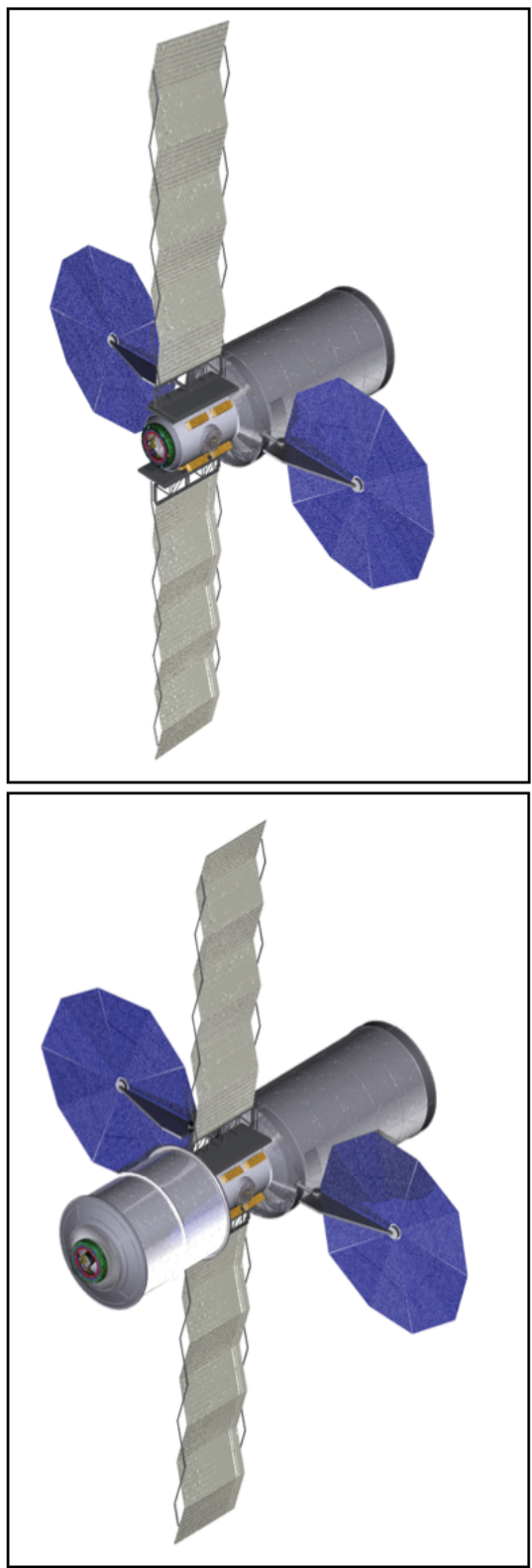

\begin{tabular}{|c|c|}
\hline Design Constraints/Parameters & \\
\hline Pressurized Volume & $\sim 117 \mathrm{~m}^{3}$ \\
\hline Habitable Volume & $\sim 65 \mathrm{~m}^{3}$ \\
\hline Cabin Pressure & $70.3 \mathrm{kPa}$ \\
\hline Crew Capacity & 4 \\
\hline Crewed Mission Duration & $60 \mathrm{~d}$ \\
\hline EOL Solar power generation & $25.8 \mathrm{~kW}$ \\
\hline Power load during battery operation & $15.3 \mathrm{~kW}$ \\
\hline Average TRL & 7.7 \\
\hline TRL 9 / Heritage & $43 \%$ \\
\hline ECLSS Closure - Water & Closed Loop \\
\hline ECLSS Closure - Air & Closed Loop \\
\hline Habitat Structure & Rigid Cylinder \\
\hline Habitat Length & $11.5 \mathrm{~m}$ \\
\hline Habitat Diameter & $4.5 \mathrm{~m}$ \\
\hline Mass Growth Allocation (MGA)* & $12.04 \%$ \\
\hline Project Manager's Reserve & $10 \%$ \\
\hline Design Constraints/Parameters & \\
\hline Pressurized Volume & $\sim 193 \mathrm{~m}^{3}$ \\
\hline Habitable Volume & $\sim 90 \mathrm{~m}^{3}$ \\
\hline Cabin Pressure & $70.3 \mathrm{kPa}$ \\
\hline Crew Capacity & 4 \\
\hline Crewed Mission Duration & $500 \mathrm{~d}$ \\
\hline EOL Solar power generation & $34 \mathrm{~kW}$ \\
\hline Power load during battery operation & $20 \mathrm{~kW}$ \\
\hline Average TRL & 7.7 \\
\hline TRL 9 / Heritage & $47 \%$ \\
\hline ECLSS Closure - Water & Closed Loop \\
\hline ECLSS Closure - Air & Closed Loop \\
\hline Habitat Structure & Rigid Cylinder \\
\hline Habitat Length & $18 \mathrm{~m}$ \\
\hline Habitat Diameter & $4.5 \mathrm{~m}$ \\
\hline Mass Growth Allocation & $13.62 \%$ \\
\hline Project Manager's Reserve & $10 \%$ \\
\hline
\end{tabular}

\begin{tabular}{|c|c|}
\hline Category & Mass (kg) \\
\hline Structures & 9,002 \\
\hline Propulsion & 0 \\
\hline Power & 698 \\
\hline Avionics & 1,177 \\
\hline Thermal & 2,780 \\
\hline Environment Protection & 4,175 \\
\hline ECLSS & 4,379 \\
\hline Crew Systems & 690 \\
\hline EVA & 272 \\
\hline Science & 0 \\
\hline Dry Mass & 23,173 \\
\hline Stowed Provisions & 1,240 \\
\hline Consumables & 1,267 \\
\hline Non-Propellant Fluids & 457 \\
\hline Inert Mass & 2,963 \\
\hline Total Less Propellant & 26,136 \\
\hline Propellant & 0 \\
\hline Wet Mass & 26,136 \\
\hline Project Mgrs Reserve (10\%) & 2,614 \\
\hline Total & 28,750 \\
\hline Category & Mass (kg) \\
\hline Structures & 14,116 \\
\hline Propulsion & 0 \\
\hline Power & 924 \\
\hline Avionics & 1,321 \\
\hline Thermal & 2,868 \\
\hline Environment Protection & 4,826 \\
\hline ECLSS & 6,890 \\
\hline Crew Systems & 807 \\
\hline EVA & 272 \\
\hline Science & 0 \\
\hline Dry Mass & 32,022 \\
\hline Stowed Provisions & 2,766 \\
\hline Consumable Fluids & 6,187 \\
\hline Non-Propellant Fluids & 457 \\
\hline Inert Mass & 9,409 \\
\hline Total Less Propellant & 41,430 \\
\hline Propellant & 0 \\
\hline Wet Mass & 41,430 \\
\hline Project Mgrs Reserve (10\%) & 4,143 \\
\hline Total & 45,573 \\
\hline
\end{tabular}

Figure 14. Configuration B for the ISS Derived HAB + Airlock + MPLM. The two ISS derived habitats shown provide habitation for 4-crewon 60-day missions, or 500-daymissions with the addition of a MPLM. The habitat has a docking port and a berthing port to accommodate the Orion MPCV and a EUS propulsion element. The connecting tunnel is an airlock and includes anEVA hatch with access to external utilities, including power and thermal systems. The habitat is designed to accommodate all life support systems in the HAB module. The MPLM can be sized to provide consumables for mission durations beyond 60 days. 


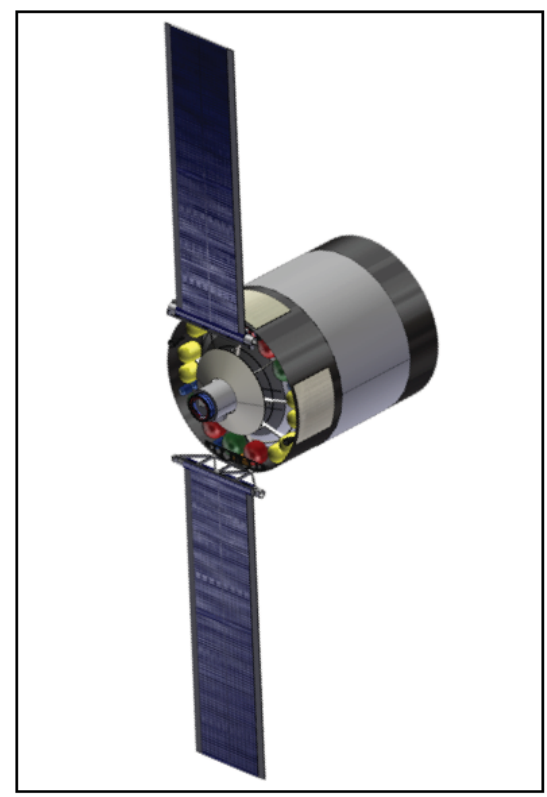

\begin{tabular}{|l|c|}
\hline Design Constraints/Parameters & \\
\hline Pressurized Volume & $\sim 496 \mathrm{~m}^{3}$ \\
Habitable Volume & $101.3 \mathrm{kPa}$ \\
\hline Atmospheric Pressure & \\
\hline Crew Capacity & $180 \mathrm{~d}$ \\
\hline Crewed Mission Duration & \\
\hline EOL Solar power generation & $22 \mathrm{~kW}$ \\
\hline Power load during battery operation & $3.3 \mathrm{~kW}$ \\
\hline Average TRL & \\
\hline TRL 9 / Heritage & 7.9 \\
\hline ECLSS Closure - Water & $50 \%$ \\
\hline ECLSS Closure - Air & Closed Loop \\
\hline Habitat Structure & Closed Loop \\
\hline Habitat Length & Rigid Cylinder \\
\hline Habitat Diameter & $13.5 \mathrm{~m}$ \\
\hline Mass Growth Allocation & $8.4 \mathrm{~m}$ \\
\hline Project Manager's Reserve & $9.90 \%$ \\
\hline
\end{tabular}

\begin{tabular}{|l|c|}
\hline Category & Mass (kg) \\
\hline Structures & 9,596 \\
\hline Propulsion & 0 \\
\hline Power & 1,364 \\
\hline Avionics & 1,736 \\
\hline Thermal & 1,007 \\
\hline Environment Protection & 0 \\
\hline ECLSS & 2,491 \\
\hline Crew Systems & 599 \\
\hline EVA & 488 \\
\hline Science & 0 \\
\hline Dry Mass & $\mathbf{1 7 , 2 8 0}$ \\
\hline Stowed Provisions & 870 \\
\hline Consumables & 1,566 \\
\hline Nonpropellant Fluids & 91 \\
\hline Inert Mass & $\mathbf{2 , 5 2 7}$ \\
\hline & \\
\hline Total Less Propellant & $\mathbf{1 9 , 8 0 7}$ \\
\hline Propellant & 0 \\
\hline Wet Mass & $\mathbf{1 9 , 8 0 7}$ \\
\hline Project Mgrs Reserve & 1,981 \\
\hline Total & $\mathbf{2 1 , 7 8 8}$ \\
\hline Cata & \\
\hline
\end{tabular}

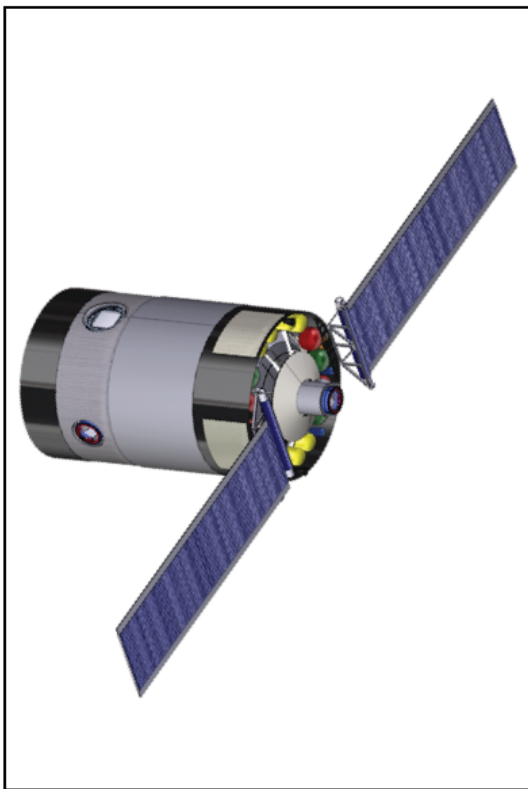

\begin{tabular}{|l|c|}
\hline Design Constraints/Parameters & \\
\hline Pressurized Volume & $\sim 662 \mathrm{~m}^{3}$ \\
\hline Habitable Volume & $\sim 519 \mathrm{~m}^{3}$ \\
\hline Atmospheric Pressure & $101.3 \mathrm{kPa}$ \\
\hline Crew Capacity & 4 \\
\hline Crewed Mission Duration & $180 \mathrm{~d}$ \\
\hline EOL Solar power generation & $22 \mathrm{~kW}$ \\
\hline Power load during battery operation & $3.3 \mathrm{~kW}$ \\
\hline Average TRL & 7.9 \\
\hline TRL 9 / Heritage & $50 \%$ \\
\hline ECLSS Closure - Water & Closed Loop \\
\hline ECLSS Closure - Air & Closed Loop \\
\hline Habitat Structure & Rigid Cylinder \\
\hline Habitat Length & $16.5 \mathrm{~m}$ \\
\hline Habitat Diameter & $8.4 \mathrm{~m}$ \\
\hline Mass Growth Allocation & $9.61 \%$ \\
\hline Project Manager's Reserve & $10 \%$ \\
\hline
\end{tabular}

\begin{tabular}{|l|c|}
\hline Category & Mass (kg) \\
\hline Structures & 13,902 \\
\hline Propulsion & 0 \\
\hline Power & 1,364 \\
\hline Avionics & 2,154 \\
\hline Thermal & 1,102 \\
Environment Protection & 0 \\
\hline ECLSS & 2,572 \\
\hline Crew Systems & 702 \\
\hline EVA & 570 \\
\hline Science & 0 \\
\hline Dry Mass & $\mathbf{2 2 , 3 6 6}$ \\
\hline Stowed Provisions & 870 \\
\hline Consumables & 1,566 \\
\hline Nonpropellant Fluids & 138 \\
\hline Inert Mass & $\mathbf{2 , 5 7 4}$ \\
\hline Total Less Propellant & $\mathbf{2 4 , 9 4 0}$ \\
\hline Propellant & 0 \\
\hline Wet Mass & $\mathbf{2 4 , 9 4 0}$ \\
\hline Project Mgrs Reserve & $\mathbf{2 , 4 9 4}$ \\
\hline Total & $\mathbf{2 7 , 4 3 4}$ \\
\hline
\end{tabular}

Figure 15. Configuration C-1 Minimum Capability Habitat and C-2 Full Capability Habitat. The two SLS derived habitatconfigurations shown in this summary provide habitation for 4-crew on three missions of 60 days, or varying lengths up to 180 days total. Additional missions and duration times are possible with logistic flights to provide consumables and spares. The primary destination is a lunar DRO. The propulsion system was removed for comparison purposes, but originally sizedfor refueling to permit a transfer to EML1 or EML2 orbit and orbital maintenance for up to 10 years. The C-1 Minimum Capability has one docking port on the end of the airlock for the Orion MPCV. The C-2 Full Capability has five additional docking ports, one on the opposite end dome and four radial ports to support logistics, FlexCraft, landers, and international elements. 


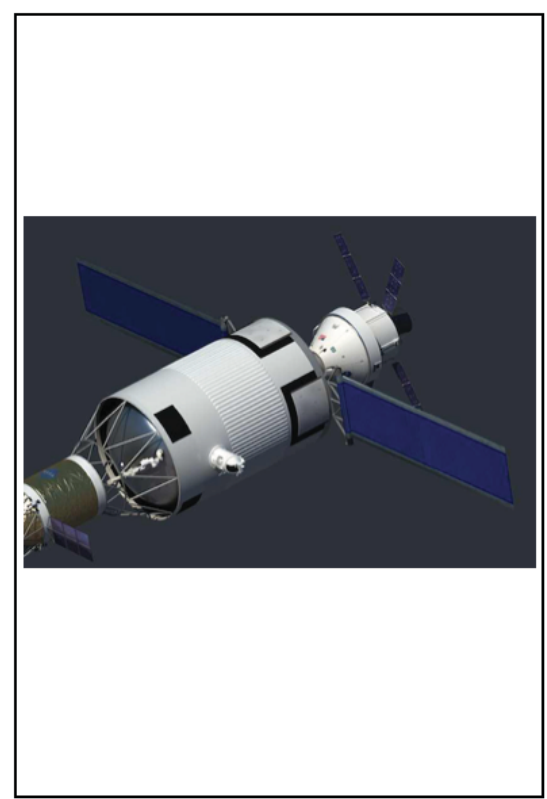

\begin{tabular}{|l|c|}
\hline Design Constraints/Parameters & $\sim 662 \mathrm{~m}^{3}$ \\
\hline Pressurized Volume & $\sim 440 \mathrm{~m}^{3}$ \\
\hline Habitable Volume & $101.3 \mathrm{kPa}$ \\
\hline Atmospheric Pressure & 4 \\
\hline Crew Capacity & $180 \mathrm{~d}$ \\
\hline Crewed Mission Duration & $22 \mathrm{~kW}$ \\
\hline EOL Solar power generation & $3.3 \mathrm{~kW}$ \\
\hline Power load during battery operation & 7.9 \\
\hline Average TRL & $50 \%$ \\
\hline TRL 9 / Heritage & Closed Loop \\
\hline & Closed Loop \\
\hline ECLSS Closure - Water & \\
\hline ECLSS Closure - Air & Rigid Cylinder \\
\hline Habitat Structure & $16.5 \mathrm{~m}$ \\
\hline Habitat Length & $8.4 \mathrm{~m}$ \\
\hline Habitat Diameter & $9.61 \%$ \\
\hline Mass Growth Allocation & $10 \%$ \\
\hline Project Manager's Reserve & \\
\hline
\end{tabular}

\begin{tabular}{|l|c|}
\hline Category & Mass (kg) \\
\hline Structures & 12,669 \\
\hline Propulsion & 0 \\
Power & 1,811 \\
\hline Avionics & 2,058 \\
\hline Thermal & 1,095 \\
\hline Environment Protection & 0 \\
\hline ECLSS & 2,696 \\
\hline Crew Systems & 1,310 \\
\hline EVA & $\mathbf{7 5 0}$ \\
\hline Science & 0 \\
Dry Mass & $\mathbf{2 2 , 3 8 9}$ \\
\hline Stowed Provisions & 4,654 \\
\hline Consumables & 13,102 \\
\hline Nonpropellant Fluids & 0 \\
\hline Inert Mass & $\mathbf{1 7 , 7 5 6}$ \\
\hline & \\
\hline Total Less Propellant & $\mathbf{4 0 , 1 4 5}$ \\
\hline Propellant & 0 \\
\hline Wet Mass & $\mathbf{4 0 , 1 4 5}$ \\
\hline Project Mgrs Reserve & $\mathbf{4 , 0 1 4}$ \\
\hline Total & $\mathbf{4 4 , 1 5 9}$ \\
\hline
\end{tabular}

Figure 16. Configuration C-3 for the Mars Transit Habitat. The SLS derived habitat configuration shown in this summary provides habitation for 6-crewon 1000-day mission durations. The mission is launched from lunar DRO to Mars orbit and returns to the lunar DRO for refurbishment. Resupply at the lunar DRO provides for multiple mission capabilities for a possible 30-year lifetime. The C-3 Mars Transit Habitat has three docking ports, one on the airlock at the forward end dome for the Orion MPCV, and two radial ports to support a FlexCraft and a Mars lander.

\section{Ack nowle dgments}

The authors thank the NASA Advanced Exploration Systems (AES) Program for their support through the AES Deep Space Habitat and Exploration Augmentation Module projects managed through the Johns on Space Center and the concept demonstrator tas k managed at the Marshall Space Flight Center. In addition, the authors thank the SLS Advanced Development Office, the Engineering Directorate, and the 30-plus engineers that supported the launch vehicle, architecture, and space systems teams in the Advanced Concepts Office at the Marshall Space Flight Center.

\section{References}

${ }^{1}$ Smitherman, D., Russell, T., Griffin, B. N., et al, “Deep Space Habitat Configurations Based on International Space Station Systems," Global Space Exploration Conference, GLEX 2012.01.1.8x12219, Washington, DC, 2012.

${ }^{2}$ Griffin, B. N., Smitherman, D., Kennedy, K. J., et al., "Skylab II: Making a Deep Space Habitat from a Space Launch System Propellant Tank," AIAA Space 2012 Conference and Exposition, AIAA 2012-5207, Pasadena, CA, 2012.

${ }^{3}$ Brouphy, J., Culick, F., Friedman, L., “Asteroid Retrieval Feasibility Study,” Keck Institute for Space Studies, Jet Propulsion Laboratory, Pasadena, CA, 2012.

${ }^{4}$ International Space Exploration Coordination Group, “Global Exploration Roadmap,” NASA NP-2013-06-945-HQ, 2013.

${ }^{5}$ Griffin, B. N., "Benefits of a Single-Person Spacecraft for Weightless Operations," 42 nd International Conference on Environmental Systems, AIAA 2012-3630, San Diego, CA, 2012.

${ }^{6}$ Drake, B., ed., "Human Exploration of Mars Design Reference Architecture 5.0," NASA SP -2009-566, 2009.

${ }^{7}$ Drake, B., ed., "Human Exploration of Mars Design Reference Architecture 5.0 Addendum," NASA SP -2009-566-ADD, 2009.

${ }^{8}$ Griffin, B. N., Smitherman, D., Howe, A. S., “Internal Layout for a Cis-Lunar Habitat,” AIAA Space 2013 Conference and Exposition, AIAA 2013-5433, San Diego, CA, 2013. 